\title{
ANÁLISE COMPARATIVA DE DESEMPENHO DE ALUNOS DE ENSINO MÉDIO EM ATIVIDADE COM MODELAGEM COMPUTACIONAL EXPLORATÓRIA E ATIVIDADE TRADICIONAL SOBRE MOVIMENTO DOS CORPOS ${ }^{1}$
}

\author{
Rafael Rodrigues de Oliveira* \\ Laércio Ferracioli**
}

RESUMO: Este artigo apresenta uma investigação do desempenho que 114 estudantes que cursavam, em 2011, o $1^{\circ}$ Ano do Ensino Médio obtiveram em atividades com relações matemáticas de Média Simples e Velocidade Média no estudo do movimento retilíneo dos corpos, em um processo que envolveu dois momentos distintos e subsequentes. O primeiro momento foi caracterizado pela aplicação de atividades de modelagem computacional exploratória. Dias depois da atividade inicial, os estudantes foram submetidos a uma atividade tradicional durante a avaliação trimestral, contendo itens da atividade de modelagem. Nessa perspectiva, os resultados relatados neste trabalho mostram que o desempenho da primeira para a segunda atividade diminuiu para 51 estudantes $(\approx 44,7 \%)$, foi mantido constante para $40(\approx 35,1 \%) \mathrm{e}$ aumentou para $23(\approx 20,2 \%)$. Os resultados sugerem, ainda, que o uso da modelagem computacional exploratória, em atividades que desenvolvem estudos com relações algébricas e quantidades numéricas, pode ser uma possibilidade a ser incorporada no dia a dia da sala de aula, e não apenas em investigações pontuais e de abordagem exploratórias.

Palavras-chave: Velocidade Média. Modelagem Computacional. Desempenho.

\section{ANÁLISIS COMPARATIVO DE DESEMPEÑO DE ALUMNOS DE SECUNDARIA EN ACTIVIDAD CON MODELAJE COMPUTACIONAL EXPLORATORIA Y ACTIVIDAD TRADICIONAL ACERCA DEL MOVIMIENTO DE LOS CUERPOS}

RESUMEN: Este artículo presenta una investigación del desempeño de 114 estudiantes que cursaban en 2011 el primer año de la Secundaria en actividades con relaciones matemáticas de Media Sencilla y Velocidad Media en el estudio del movimiento rectilíneo de los cuerpos, en un proceso que tuvo dos momentos distintos y subsecuentes. El primer momento fue caracterizado por la aplicación de actividades de modelaje computacional exploratoria. Días después de la actividad inicial, los estudiantes fueron sometidos a una actividad tradicional durante la evaluación trimestral, con partes del actividad de modelaje. En esa perspectiva, los resultados relatados en este trabajo mostraron que el desempeño de la primera para la segunda actividad bajó para 51 estudiantes $(\approx 44,7 \%)$, se mantuvo constante para $40(\approx 35,1 \%)$ y aumentó para $23(\approx 20,2 \%)$. Los resultados sugieren, todavía, que el uso del modelaje computacional exploratorio en actividades que desarrollan estudios con relaciones algébricas y

DOI - http://dx.doi.org/10.1590/1983-21172015170307

* Doutor em Educação pela Universidade Federal do Espírito Santo - UFES. Professor do Estado do Espírito Santo na Escola Estadual de Ensino Fundamental e Médio Antônio José Peixoto Miguel. E_mail: rafaelfisica2000@yahoo. com.br

* * Ph.D. em Educação em Ciências, University of London. Professor Titular do Departamento de Física, do Programa de Pós-Graduação em Ensino de Física e Programa de Pós-Graduação em Educação da Universidade Federal do Espírito Santo. e-mail: laercio.ufes@gmail.com 
cuantidades numéricas, puede ser una posibilidad a ser incorporada en el día-a-día del aula, y no apenas en investigaciones puntuales y de abordaje exploratorio.

Palabras clave: Velocidad Media. Modelaje computacional. Desempeño

HIGH SCHOOL STUDENTS PERFORMANCE'S COMPARATIVE ANALYSIS BETWEEN ACTIVITY WITH COMPUTER MODELING AND TRADITIONAL EXPLORATORY ACTIVITY ABOUT BODY MOTION

ABSTRACT: This paper presents an investigation of 114 students who attended the 1st High School Year in 2011' performance in activities with mathematical relationship of Average Simple and Average Speed in the study of bodies' rectilinear motion. The process involved two distinct and subsequent moments. The first moment was characterized by the application of exploratory computer modeling activities. Approximately 4,5 days after the initial activity students were submmited to a traditional activity, during a quarterly assessment, containing items of the computer modeling activity. In this perspective, the results reveal that the performance decreased to 51 students $(\approx 44,7 \%)$, was held constant for $40(\approx 35,1 \%)$ and increased to $23(\approx 20,2 \%)$. The results also point that the use of exploratory computer modeling in activities that develop teaching of algebraic relations and numerical quantities can be a possibility to be incorporated into classroom daily life and not only in punctual and exploratory investigations.

Keywords: Average Velocity. Computer Modeling. Performance. 


\section{INTRODUÇÃO}

A educação, em seu sentido lato, é um fenômeno tipicamente social e, por ter essa natureza, é possível observar, ao longo da história, que se tornou um fenômeno de complexidade crescente, na medida em que as relações sociais também se tornaram mais complexas na sociedade contemporânea.

Nas primeiras décadas do século XXI, a produção, o armazenamento e, principalmente, a transmissão do conhecimento para as gerações futuras é, sem sombra de dúvidas, mais multíplice do que outrora fora a partilha de conhecimento feita de forma oral de geração para geração, em sociedades tribais antigas: nesse cenário, todo o saber produzido pelas experiências diárias dos indivíduos não possuía um registro sistemático, e a sua preservação era feita quase exclusivamente na memória individual e coletiva dessas sociedades.

Em nosso atual contexto educacional, o fazer pedagógico possui um panorama que era inimaginável há meio século. A imersão da atual geração de crianças e jovens no oceano de informações provido pela internet e principalmente pelas redes sociais, na maioria das vezes não é transformada por eles em conhecimento; a imensa quantidade de textos, hipertextos e imagens em movimento das mídias digitais, faz-nos repensar o papel do livro didático na escola, apesar de saber-se que livro ainda é um dos pilares da nossa atual educação; a educação, com seu caráter permanente, impõe um contínuo desafio para ofertá-la; e, por fim, o caráter cada vez mais holístico e interdisciplinar do conhecimento se opõe à sua abordagem ainda especializada e disciplinar.

Dentro desse cenário, é possível observar que a escola possui desafios para os quais não existem respostas prontas e muito menos definitivas. Porém, existe uma certeza: o modelo escolar fundamentado pelas gerações passadas, com foco na disciplina, em métodos rígidos de ensino, hierarquizada, no qual o professor, auxiliado pelo livro didático, era a principal fonte de conhecimento, está cada vez mais "desconectado" do nosso atual contexto educacional.

É preciso buscar caminhos para que a escola possa adequar-se a todos esses desafios que o mundo atual vem nos impondo, ou seja, torna-se necessário estabelecer diretrizes tanto teóricas quanto metodológicas que possam levar à construção de uma prática docente que se alinhe a essa nova realidade conjuntural, promovendo uma educação capaz de preparar nossos jovens e adultos para o mundo na atualidade.

Nesse caminho, uma perspectiva de trabalho promissora é a inserção, no cotidiano escolar, de Tecnologias de Informação e Comunicação (TICs). Tais tecnologias, nas últimas décadas, modificaram intensamente as relações interpessoais, sociais, comerciais e de trabalho. Na escola não é diferente, uma vez que as TICs se mostram cada vez mais inseridas no cotidiano escolar, seja pelas iniciativas institucionais das salas de informática com/sem inter/intranet, ou a partir de iniciativas individuais com notebooks, smartphones com internet móvel ou tablets, tecnologias essas cada vez mais incorporadas no cotidiano dos estudantes. (FERRACIOLI et al., 2012)

Dentro desse panorama escolar, este artigo relata um estudo ocorrido em novembro de 2011 que explorou o uso das TICs no cotidiano escolar. A proposta 
consistiu de uma atividade sobre movimento retilíneo, utilizando computadores da sala de informática, a partir dos conceitos de Modelos, Modelagem, Modelagem Computacional \& Softwares de Modelagem Computacional. A perspectiva de trabalho foi estruturar e investigar diferentes fazeres pedagógicos, associando conteúdos específicos com os conceitos acima em uma perspectiva de ciência como investigação (FERRACIOLI et al., 2012) e, dessa forma, observar e relatar possibilidades e limitações dessas atividades no cotidiano da escola.

\section{Referencial teórico}

A educação básica parece constituir um desafio na atual conjuntura educacional brasileira. Assim, podem-se citar, por exemplo, os resultados obtidos por nossos estudantes sobre seus conhecimentos em leitura, ciências e matemática ao término do ensino fundamental e início do Ensino Médio relatado pelo PISA ${ }^{2}$, que mostra que, "em um ranking de 65 países somos o $53^{\circ}$ colocado em Leitura e Ciências e $57^{\circ}$ em Matemática” (GOMIDE, 2010).

Esse fato não causa espanto no atual cenário educacional brasileiro, pois o que se observa empiricamente na maioria das escolas de ensino básico, com raras exceções, é um ensino pautado no uso dos livros didáticos e dos pincéis para quadro branco, contrapondo a premente demanda de integração de laboratórios de ciências e metodologias inovadoras de ensino e aprendizagem, ainda, pouco encontrada no cotidiano escolar.

É claro que o livro didático ainda se constitui como base para o ensino em qualquer sistema educacional, porém não se pode desprezar o fato de que, na atualidade, os jovens vivem em uma cultura na qual imagens aliadas aos recursos audiovisuais e tecnológicos têm grande apelo visual. Segundo Aranha (2003, p. 235):

A universalização da imagem não se restringe ao mundo do lazer e do entretenimento, mas dá origem a outra forma de pensar, distante do saber tradicional, em que as informações derivam mais da transmissão oral ou da escrita.

Contudo, na dimensão educacional, não é desejável que essa perspectiva seja um fim em si mesma. Ou seja, o seu uso deve ocorrer paralelamente à transmissão oral e escrita no contexto da escola, pois, de outra forma, pse deixar a dimensão da aprendizagem da informação minimizada e assim, não promover a sua transformação do conhecimento no processo ensino-aprendizagem, estabelecido a partir do fazer dos próprios estudantes.

Assim, a integração de atividades escolares com o computador pode se tornar, paulatinamente, uma opção natural para o cotidiano escolar, uma vez que, além de suportar várias mídias audiovisuais, a sua utilização pode ser, de acordo com a estratégia adotada pelo professor, associada ao signo oral e escrito. 


\section{Modelos e modelagem}

Para se definir o que é modelagem será necessário, em primeiro lugar, definir o que é um modelo, embora essa definição não seja simples e dependa do contexto de sua aplicação ou utilização. Assim, no contexto de interesse desse trabalho, "um modelo pode ser definido como a representação de uma ideia, um objeto, um evento, um processo ou um sistema" (BOULTER; GILBERT, 1998, p. 16.

Essa definição pode evoluir em direção ao entendimento de modelos tanto como representações concretas, tais como um objeto, uma maquete, um protótipo ou um sistema físico, quanto ao entendimento de modelos como representações abstratas, como um pensamento, uma ideia, um evento ou um processo. Assim, a partir desse conceito pode-se definir modelagem como a atividade humana de construir modelos, sejam eles concretos ou abstratos (FERRACIOLI et al., 2012).

Os modelos construídos, por sua vez, são os mais variados possíveis, com aplicabilidade nas mais diversas atividades humanas. O processo de modelagem pode abranger desde um simples jogo ou brinquedo lúdico, por exemplo, um quebra-cabeça em que as crianças montam figuras peça por peça, até uma construção abstrata e sofisticada do pensamento humano que se manifesta na sua forma mais precisa pelo pensamento científico. Um exemplo dessa construção abstrata é a geometria de Euclides, ou geometria euclidiana, que é baseada em cinco axiomas e alguns objetos matemáticos, tais como ponto, reta e ângulo.

Apesar de toda a variedade e aplicabilidade dos modelos e do processo de modelagem, podem-se destacar, segundo Ogborn e Miller (1994), pelo menos, três características comuns a todos os modelos, a saber: 1) uma coisa é usada no lugar de outra; 2) simplificação e idealização dos recursos de modelagem e, por fim, 3) tendência de usar os recursos de modelagem para os nossos próprios objetivos.

A primeira característica apontada pelos autores pode ser entendida a partir de uma melhor análise da frase. Uma coisa, o modelo, é usada no lugar de outra, mundo que nos cerca. Assim, a modelagem faz o uso de uma gama de objetos, variáveis, relações e eventos, com a finalidade de representar sistemas e/ou processos do mundo ao nosso redor.

A segunda característica é a simplificação e a idealização dos recursos de modelagem. Toda a atividade de modelagem, seja ela lúdica ou não, faz o uso de simplificações e idealizações das características, relações ou componentes dos sistemas que se queira representar; "essas características mudam ou evoluem com o tempo, mas são sempre ideais" (OGBORN; MILLER, 1994, p. 35).

Finalmente, toda a atividade de modelagem começa com o interesse de se construir e/ou entender algum fenômeno ou processo da natureza. Esse interesse é sempre o de utilizar os recursos de modelagem para os nossos próprios objetivos, sejam eles quais forem. Por fim, essas três características comuns a todos os modelos podem ser resumidas em três palavras, representação, simplificação e benefício. 


\section{Modelagem computacional e ambientes de modelagem computacional}

Assim como a modelagem, a modelagem computacional pode ser aqui entendida como a atividade humana de criar modelos representados no computador, portanto, a partir de um software. Dessa forma, a modelagem computacional aplicada à aprendizagem exploratória de tópicos específicos em ciência pode ser feita a partir da utilização de Softwares/Ambientes de Modelagem Computacional.

Esses ambientes consistem em ferramentas computacionais que proporcionam aos estudantes a construção de modelos a partir de suas próprias concepções sobre um determinado fenômeno estudado ou mesmo a exploração de modelos já construídos por especialistas sobre esse mesmo fenômeno. Assim, "tais ferramentas computacionais estão inseridas em uma proposta educacional para sua infusão em atividades de conteúdo específico: o foco é no conhecimento e não na tecnologia” (FERRACIOLI et al., 2012, p. 698.

Nesse contexto, a modelagem computacional é entendida como o elo para a construção de uma perspectiva de trabalho que promova o engajamento do estudante no processo de ensino e aprendizagem, uma vez que a natureza da modelagem propicia a construção e/ou exploração de mundos artificiais, podendo levar o estudante a se engajar no processo de aprendizagem por iniciativa própria, ou seja, no processo de aprendizagem exploratória em física (FERRACIOLI et al., 2012).

Uma possível classificação desses ambientes, segundo alguns autores, é formulada, levando-se em consideração o raciocínio empregado na construção dos modelos nesses ambientes de modelagem, tal como apresentado no Quadro 01.

Quadro 1 - Classificação e Principais Características dos Ambientes de Modelagem Computacionais

\begin{tabular}{|l|l|}
\hline Classificação & \multicolumn{1}{c|}{ Principais Características } \\
\hline $\begin{array}{l}\text { Ambientes de Modelagem } \\
\text { Quantitativos }\end{array}$ & $\begin{array}{l}\text { "São ambientes com enfoque no cálculo de valores } \\
\text { de variáveis dependentes, por meio de suas relações } \\
\text { algébricas (MULINARI, 2006) e, também, denomi- } \\
\text { nados de ambientes de modelagem matemática;" }\end{array}$ \\
\hline $\begin{array}{l}\text { Ambientes de Modelagem } \\
\text { Semiquantitativos }\end{array}$ & $\begin{array}{l}\text { 'São ambientes com enfoque no entendimento de } \\
\text { relações causais entre variáveis do sistema e a aná- } \\
\text { lise da tendência do efeito nessas relações - acrés- } \\
\text { cimo e decréscimo - mas não no conhecimento } \\
\text { dos valores numéricos das relações algébricas } \\
\text { (MARINS, 2009);" }\end{array}$ \\
\hline
\end{tabular}




\begin{tabular}{|l|l|}
\hline $\begin{array}{l}\text { Ambientes de Modelagem } \\
\text { Qualitativos }\end{array}$ & $\begin{array}{l}\text { "São ambientes em que os modelos são construídos } \\
\text { sem a especificação de variáveis, relações algébricas } \\
\text { ou quantidades, mas pela especificação dos seus } \\
\text { constituintes básicos e das regras que determinam } \\
\text { seus comportamentos (FEHSENFELD, 2010)." }\end{array}$ \\
\hline
\end{tabular}

Para a implantação da modelagem computacional no contexto educacional, é possível utilizar, segundo Camiletti (2001), duas propostas de atividades a partir dos ambientes de modelagem computacional, conforme apresentado no Quadro 2.

Quadro 2 - Propostas de Trabalho com Modelagem Computacional no Contexto Escolar

\begin{tabular}{|l|l|}
\hline Classificação & \multicolumn{1}{c|}{ Principais Características } \\
\hline Atividade Expressiva & $\begin{array}{l}\text { O estudante é levado a construir seu próprio modelo, } \\
\text { a partir de suas concepções sobre um fenômeno ou } \\
\text { sistema (CAMLETTI, 2001). }\end{array}$ \\
\hline Atividade Exploratória & $\begin{array}{l}\text { O estudante é levado a explorar um modelo pre- } \\
\text { viamente construído por um professor ou espe- } \\
\text { cialista sobre um determinado fenômeno (CAMI- } \\
\text { LETTI, 2001). }\end{array}$ \\
\hline
\end{tabular}

No presente estudo, foi desenvolvida uma Atividade Exploratória a partir da manipulação, feita pelos estudantes, de um modelo construído pelo professor, no Ambiente de Modelagem Computacional Qualitativo denominado ModeLab ${ }^{2 D}$ acrônimo de Modelling Labotatory 2D $D^{3}$. O tema desenvolvido nessa atividade foi o Movimento Retilíneo dos Copos, mais especificamente o movimento de três corpos: uma moto, um carro e um trem. O principal objetivo da atividade foi desenvolver com os alunos, de forma quantitativa, as relações matemáticas de Média Simples e Velocidade Média.

\section{0 computador associado aos conceitos de modelos, modelagem e ambientes de mode- lagem computacional: alguns resultados da literatura}

A partir do que foi exposto nas duas seções anteriores, serão apresentados aqui resultados de trabalhos realizados ao longo dos últimos dez anos na área de modelagem computacional aplicada especificamente ao ensino de Física ${ }^{4}$. Dessa forma, os resultados foram organizados em ordem cronológica e buscaram dialogar com os resultados do presente estudo, auxiliando, assim, as interpretações dos dados produzidos nesta pesquisa. 
Magalhães e colaboradores (2002), em um estudo sobre Movimento dos Corpos, auxiliados por uma ferramenta de modelagem computacional denominada SAM, observaram, a partir de uma avaliação diagnóstica, que, em geral, os alunos do Ensino Médio das escolas públicas envolvidas na pesquisa não apresentaram pré-requisitos em matemática para o estudo do tópico proposto. Dessa forma, foi necessário que os professores de Física complementassem tal conhecimento em suas aulas. Contudo, os autores destacam que:

Com uso do software SAM os alunos se sentem motivados a analisar o mundo real através do programa fazendo dessa forma, que tal tecnologia pode se constituir como uma ferramenta de aquisição de conhecimento para os alunos. (MAGALHÃES et al., 2002 p. 101)

Assim, para esses autores, apesar de muitas vezes os alunos não apresentarem os pré-requisitos matemáticos necessários para o estudo de temas específicos em Física, o uso de softwares podem, mesmo assim, gerar em tais educandos motivação para o engajamento nas atividades e temas específicos da disciplina, nesse caso, o Movimento dos Corpos.

Em uma abordagem histórico-conceitual, Fiolhais e Trindade (2003) destacam que o uso do computador no ambiente escolar pode, entre outras coisas, diversificar tanto as estratégias didáticas para os professores, quanto as possibilidades de aprendizagem para os alunos. Especificamente, as formas interativas de utilização dessas tecnologias parecem promissoras para o ensino de ciências. Tais autores destacam também que o real estudo sobre a eficácia dessas tecnologias permanece, em larga escala, ainda por fazer. E, por fim, pontuam que:

Naturalmente que as tecnologias por si não bastam (nunca bastou!), cabendo aos professores um papel essencial na forma de rendibilização desses meios pedagógicos e aos alunos, como é óbvio, um esforço efetivo de aprendizagem. (FIOLHAIS; TRINDADE, 2003, p. 271)

Assim, apesar dos computadores ofertarem novas possibilidades de ensino e de aprendizagem e, também, formas interativas de atividades, ainda se faz necessária uma investigação em larga escala sobre as reais potencialidades que tal ferramental oferece para a abordagem de conteúdos escolares em geral, trabalho esse que deve incluir, ainda, o refletir sobre o papel do professor, assim como o do aluno, ao longo de atividades escolares que envolvam a modelagem computacional.

Assim, Dorneles, Araújo e Veit (2006), em um estudo sobre o uso do computador para a aprendizagem significativa de conceitos básicos de circuitos elétricos, estabelecem e definem uma das possibilidades do uso do computador, destacando:

A proposta didática com o uso do computador associado ao conceito de modelagem computacional não substitui as atividades experimentais, mas, pelo contrário, acrescenta outras situações para que o aluno explore os conteúdos em questão. (DORNELES; ARAÚJO; VEIT, 2006, p. 496) 
Dessa forma, pode-se argumentar que, em muitas situações, uma nova abordagem de conteúdo, tal como a da modelagem computacional, pode oferecer novas possibilidades de ensino e também de aprendizagem. Assim, não se trata de substituir as formas tradicionais de abordagem de conteúdos, mas, sim, buscar novas alternativas de explora-los.

Nessa mesma direção, em estudo sobre a utilização da modelagem computacional para a aprendizagem das Leis de Gauss e Ampère no Ensino Superior, Araújo; Veit; Moreira (2007) destacam que:

Não se consegue determinar a importância individual de cada estratégia didática nos pro $\neg$ cessos de ensino e aprendizagem, porém, pode-se perceber claramente quão positivo foi para o aprendizado dos conteúdos de Física a possibilidade de interação e de visualização fornecidas pelas simulações. (ARAÚJO; VEIT; MOREIRA, 2007, p. 618., 2007).

Assim, estudos nessa área revelam uma segunda potencialidade para a modelagem computacional - oferecer simulações dinâmicas para a visualização de modelos teóricos científicos de fenômenos que, muitas vezes, podem ser trabalhados experimentalmente em laboratórios de ciências, porém sem oferecer as visualizações concretas das estruturas teóricas que expliquem tais fenômenos, por exemplo, as linhas de Campos Elétricos e Magnéticos associados às leis de Gauss e Ampère, respectivamente.

Outro aspecto relevante é obtido ao se analisar a opinião de alunos sobre a utilização de simuladores, imagens e animações no ensino/aprendizagem de Óptica, tal como relatado por Heckler, Saraiva e XXX Filho?? (2007):

Os materiais didáticos baseados no computador e na modelagem computacional vão ao encontro da realidade da grande maioria deles, proporcionando um ambiente de estímulo, motivação e envolvimento no processo de ensino/aprendizagem, fazendo com que os alunos participem ativamente da aquisição de informações e construção do conhecimento. E, um ponto positivo percebido com tais ferramentas, é que despertou um maior interesse pelas aulas de Física na visão de 95\% dos alunos. (HECKLER; SARAIVA; FILHO, 2007, p. 273)

Contudo, os autores advertem para o fato de que o trabalho com o computador e as simulações computacionais tem suas limitações como recurso didático, destacadas por ele a partir das suas observações e dos relatos dos alunos como:

Facilidade de distração. Além do forte apelo apresentado pelas imagens móveis, de certa maneira, desestimular a leitura dos textos explicativos, levando os alunos a ficarem apenas observando as imagens e as simulações no material, também existe a grande possibilidade de eles desviarem totalmente sua atenção do assunto da aula para utilizarem outros recursos disponibilizados pelo computador e que podem ser mais atraentes do que a aula. (HECKLER; SARAIVA; FILHO, 2007, p. 273) 
Assim, a visualização dinâmica que a modelagem computacional oferece pode, também, constituir-se em uma característica negativa. Cabe preponderantemente ao professor, portanto, levar os alunos a se engajarem nas atividades, para que as animações, simulações e visualizações dinâmicas não superem a dimensão educacional das atividades escolares.

Por outro lado, em estudo sobre um tópico de Física Moderna mediante a utilização de um Objeto de Aprendiragem (AO) denominado Pato Quântico, utilizando uma perspectiva que pode ser classificada como modelagem exploratória, Sales e colaboradores (2008) concluíram que:

Tais objetos de aprendizagem podem apresentar-se como uma ferramenta de auxilio ao professor em sala de aula, colaborando para desmistificar a aprendizagem em Física, considerada difícil, e possibilitando uma melhor compreensão dos fenômenos quânticos. (SALES et al., 2008, p. 10)

Dessa forma, a modelagem computacional pode ser uma ferramenta que torne o aprendizado de tópicos de Física Moderna plausíveis, também, para o Ensino Médio e não apenas no Ensino Superior.

Por fim, Ferracioli et al. (2012), abordando a integração de "Ambientes de modelagem computacional no aprendizado exploratório de física”, destaca que a integração de ambientes de modelagem computacional quantitativos, semiquantitativos e qualitativos no ambiente escolar vem se revelando uma estratégia didática promissora, na medida em que o foco é o conhecimento e não a tecnologia.

Assim, ao expor os resultados desses trabalhos, ficam evidentes alguns pontos que podem nortear e dar subsídios teóricos para trabalhos futuros na área. Pode-se destacar, inicialmente, que a modelagem computacional possui uma considerável gama de aplicação em relação aos conteúdos que podem ser trabalhados com os softwares. Os conteúdos vão desde Movimento dos Corpos, até tópicos de Física Moderna. Nessa mesma linha de raciocínio, há outro aspecto relevante que pode ser observado nesses trabalhos - o fato de a modelagem computacional ter aplicabilidade desde o Ensino Médio até o Ensino Superior.

Entre as potencialidades que a modelagem computacional pode oferecer às práticas pedagógicas em salas de aula, esses trabalhos destacam: 1) Maior motivação/ engajamento dos alunos para executar as atividades propostas; 2) Novas possibilidades de práticas pedagógicas para o professor; 3) Novas possibilidades de aprendizagem para os alunos; 4) Novas possibilidades de abordagens de conteúdos escolares; 5) Visualização dos conteúdos e modelos científicos dos fenômenos estudados; 6) Materiais didáticos compativeis com a realidade dos alunos e, por fim, 7) Possibilidade de abordagem experimental, por meio de modelos computacionais, da Física Moderna.

Por outro lado, tal ferramental didático também traz consigo alguns desafios; entre eles, os autores destacam: 1) Avaliação em larga escala das potencialidades e limitações de tais ferramentas computacionais e 2) As visualizações ofertadas pelos modelos computacionais dinâmicos podem, de acordo com a estratégia didática adotada pelo professor, se tornar uma distração para o real objetivo das atividades - o estudo de conteúdos científicos especificos. 
Dessa forma, é importante compreender que, em tal cenário, cabe ao professor ter a sensibilidade em adotar, durante a abordagem de conteúdos de Física por meio da modelagem computacional, estratégias e metodologias que potencializem os aspectos positivos de tal arcabouço metodológico e, ao mesmo tempo, reduzam as possíveis deficiências dessa escolha metodológica para o desenvolvimento do estudo dos conteúdos específicos. Por fim, cabe ao aluno o papel preponderante de se engajar nas atividades propostas pelo professor, privilegiando o conteúdo em estudo e não apenas a forma como ele é apresentado.

\section{Concepção do estudo}

A partir dos trabalhos apresentados na sessão anterior, é possível constatar que, em estudos de tópicos específicos de Física auxiliados por ferramentas de modelagem computacional, existem possibilidades e limitações durante o processo educacional. Assim, buscou-se, neste trabalho, investigar como tais possibilidades e limitações se apresentam durante o desenvolvimento do estudo de um tópico específico de Física no cotidiano de uma escola. Mais especificamente, o presente trabalho buscou, a partir das investigações aqui relatadas, responder à seguinte questão básica de pesquisa: Como ocorre a variação do desempenho de estudantes na execução de atividades baseadas na modelagem computacional e em atividades escolares tradicionais, contendo itens da atividade de modelagem, desenvolvidas posteriormente com foco em relações matemáticas, envolvendo quantidades utilizadas em Física?

$\mathrm{Na}$ perspectiva de desenvolvimento das relações matemáticas de Média Simples e Velocidade Média no estudo do Movimento Retilineo de corpos, foi investigado como ocorreu a variação de desempenho de alunos do Ensino Médio regular quando desenvolveram esse estudo em duas perspectivas distintas, porém, complementares: uma auxiliada pela modelagem computacional exploratória e outra em um formato escolar tradicional com "prova" aplicada em um momento posterior.

\section{A estruturação do estudo}

O estudo foi estruturado a partir de Módulos Educacionais que podem ser definidos como "material a ser utilizado no estudo de um determinado fenômeno, organizado em três níveis: objetivo, conteúdo instrucional e prática e avaliação" (FERRACIOLI, 2004, p. 42). O Objetivo visa promover o entendimento e aprofundamento de um determinado fenômeno a partir de algum recurso didático, como um ambiente de modelagem computacional, um site ou uma mídia; o Conteúdo Instrucional consiste em uma abordagem teórica e experimental sobre um determinado fenômeno, e a Prática \& Avaliação consiste na utilização de um recurso para o desenvolvimento das atividades experimentais mediante um roteiro com o detalhamento das atividades e perguntas sobre o que foi desenvolvido. 


\section{0 módulo educacional}

O módulo educacional desenvolvido para esse estudo constituiu-se de duas partes: o Modelo Computacional e o Roteiro de Atividades. O modelo computacional desenvolvido no Ambiente de Modelagem Computacional Qualitativo

ModeLab ${ }^{2}$ Fehsenfeld (2010), que pode ser parcialmente visualizado na Figura 01, teve o objetivo de promover o entendimento para os alunos das relações matemáticas associadas ao movimento retilíneo dos corpos, com enfoque no cálculo da média simples da variável tempo e na velocidade média. Para isso, os estudantes simulavam, cinco vezes, o modelo que continha três veículos distintos: um Trem Azul, um Carro Vermelho e uma Moto Preta. Os automóveis amarelos representam o trânsito normalmente enfrentado por carros e motos nas grandes cidades. Dessa forma, essa parte cumpre o Objetivo do Módulo Educacional.

Figura 1 - Modelo sobre movimento retilíneo dos corpos desenvolvido no ModeLab ${ }^{20}$

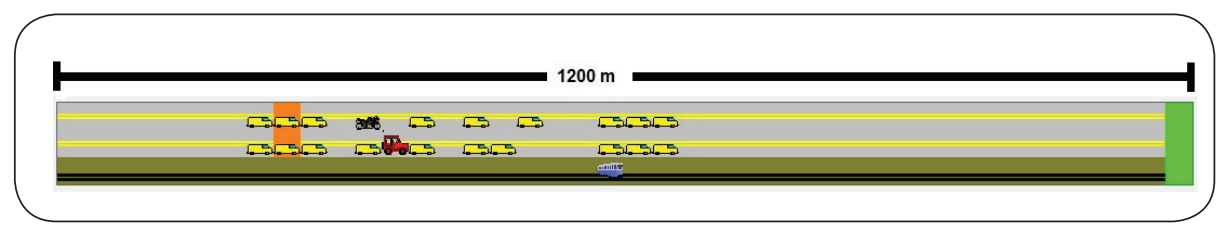

Fonte: Fonte Modelab 2D

A segunda parte é o Roteiro de Atividades que, por sua vez, tem o objetivo de promover uma abordagem teórica e prática para a atividade de modelagem computacional exploratória, bem como produzir os dados para esse estudo, a partir das respostas dadas pelos estudantes, cumprindo, assim, as etapas de Conteúdo Instrucional e Prática \& Avaliação desse Módulo Educacional.

O Roteiro de Atividades, que está ilustrado na Figura $2^{5}$, foi estruturado em três páginas com um total de quatro seções, sendo que as três primeiras, Introdução, Apresentação do Modelo Computacional e Problematização, objetivaram uma abordagem teórica do tema. Na quarta seção, Explorando o Modelo, foi desenvolvida uma abordagem prática da temática em estudo, a partir de simulações, coleta de dados, manipulação matemática dos dados produzidos nas simulações e conclusões. 
Figura 2 - Estrutura do roteiro de atividades desenvolvido para o Módulo Educacional

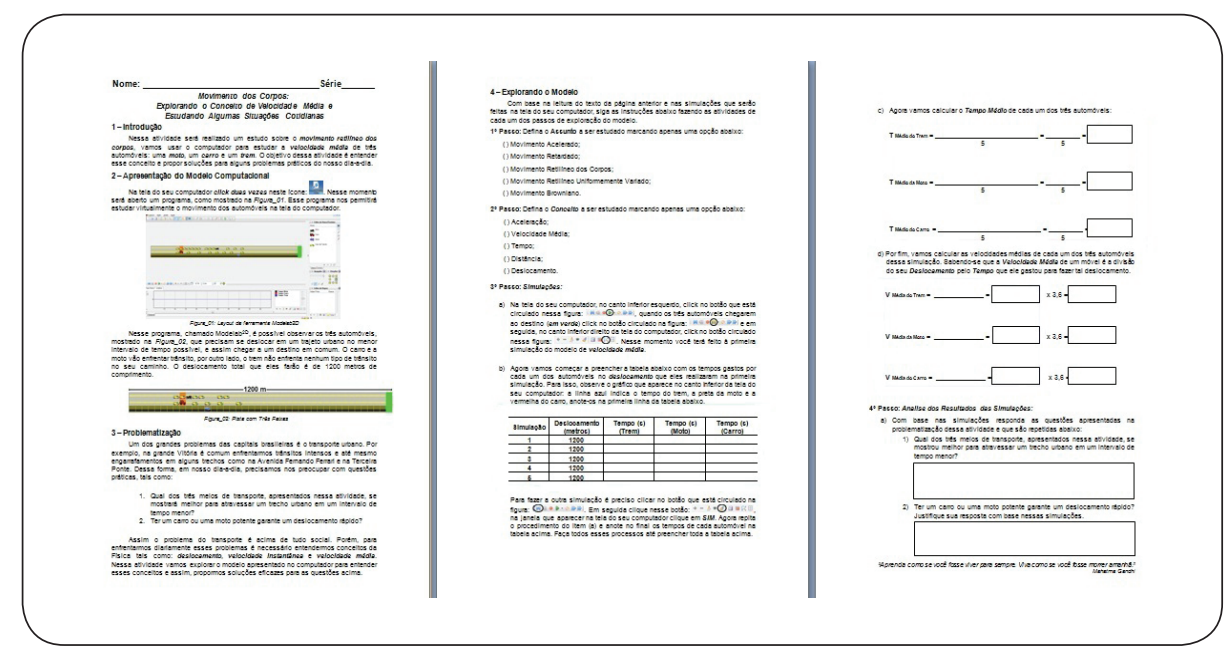

Esse Roteiro produzido para a coleta de dados.

\section{Amostragem}

Para a realização do estudo, trabalhou-se com uma amostra composta por quatro turmas do $1^{\circ}$ Ano Matutino do Ensino Médio de uma escola pública de ensino fundamental e médio regulares, localizada no município da Serra/ ES. As turmas foram identificadas como: $1^{\circ} \mathrm{A}, 1^{\circ} \mathrm{B}, 1^{\circ} \mathrm{C}$ e $1^{\circ} \mathrm{D}$, totalizando 114 alunos. Para a realização da atividade de modelagem, os estudantes foram organizados em 57 duplas, sendo que a avaliação trimestral foi feita individualmente por esses mesmos alunos.

\section{0 experimento}

O experimento foi realizado entre os dias 17 e 25 de novembro de 2011, durante o horário regular de aula da escola. Os dados foram produzidos em dois momentos distintos e subsequentes, como mostrado na Tabela 01. No primeiro momento, foi aplicada a atividade de modelagem computacional, quando os estudantes seguiram o roteiro mostrado na Figura 02 - simularam o modelo no Ambiente ModeLab ${ }^{2 \mathrm{D}}$ e preencheram uma tabela com os tempos de cada móvel; em seguida, calcularam a média dos tempos de cada móvel e, finalmente, calcularam as velocidades médias dos automóveis. É importante ressaltar 
que essa atividade não foi pontuada para o cálculo da média trimestral.

Tabela 1 - Organização do experimento

\begin{tabular}{|l|l|l|l|l|l|}
\hline Série & Duplas & $\begin{array}{l}\text { Realização da } \\
\text { Atividade de } \\
\text { Modelagem }\end{array}$ & $\begin{array}{l}\text { Número de } \\
\text { Alunos }\end{array}$ & $\begin{array}{l}\text { R e a liz a ç ã o } \\
\text { da Avaliação } \\
\text { Trimestral }\end{array}$ & $\begin{array}{c}\text { Intervalo } \\
\text { de Tempo } \\
\text { Transcorrido }\end{array}$ \\
\hline $1^{\mathrm{a}}$ & 14 & $21 / 11 / 2011$ & 28 & $25 / 11 / 2011$ & 4 dias \\
\hline 1B & 16 & $18 / 11 / 2011$ & 32 & $22 / 11 / 2011$ & 4 dias \\
\hline 1C & 13 & $17 / 11 / 2011$ & 26 & $23 / 11 / 2011$ & 6 dias \\
\hline & 14 & $21 / 11 / 2011$ & 28 & $25 / 11 / 2011$ & 4 dias \\
\hline 1D & 14 & & & &
\end{tabular}

O segundo momento da coleta de dados foi realizado durante a avaliação trimestral do cronograma de atividades escolares. A avaliação foi no formato tradicional e, em uma das questões, foi fornecida uma tabela já preenchida com os tempos dos móveis idêntica à tabela do roteiro de atividades e, assim como na atividade de modelagem, foi também solicitado aos alunos o cálculo da média dos tempos e as velocidades médias de cada móvel, perfazendo, assim, um total de 6 cálculos em cada momento: 3 de tempo médio e 3 de velocidade média.

\section{Resultados e discussão}

Os resultados foram obtidos a partir da comparação entre o desempenho apresentado pelos estudantes nos dois momentos das atividades escolares, quais sejam: Atividade de Modelagem Computacional Exploratória e Avaliação Trimestral. Assim, o primeiro passo foi definir uma escala para medir o desempenho nesses dois momentos distintos, conforme mostrado na Tabela 02, lembrando que a escala definida nesta tabela é construída seguindo a lógica da interdependência entre as relações matemáticas de tempo médio e velocidade média, uma vez que o cálculo da segunda só pode estar correto 
se o cálculo da primeira também estiver.

\begin{tabular}{|l|l|}
\hline Valor & \multicolumn{1}{|c|}{ Descrição do valor associado ao desempenho } \\
\hline 9 & Todos os Seis Cálculos Corretos \\
\hline 8 & Cinco Cálculos Corretos: Três Tempos Médios e Duas Velocidades Médias \\
\hline 7 & Quatro Cálculos Corretos: Dois Tempos Médios e Duas Velocidades Médias \\
\hline 6 & Quatro Cálculos Corretos: Três Tempos Médios e Uma Velocidade Média \\
\hline 5 & Três Cálculos Corretos: Dois Tempos Médios e Uma Velocidade Média \\
\hline 4 & Três Cálculos Corretos: Três Tempos Médios \\
\hline 3 & Dois Cálculos Corretos: Um Tempo Médio e Uma Velocidade Média \\
\hline & \\
\hline
\end{tabular}

A partir da interdependência das relações matemáticas de tempo médio e velocidade média, formularam-se três critérios em hierarquia decrescente de importância: 1) números de cálculos corretos, ou seja, quanto maior o número de cálculos feitos de forma correta, maior a nota atribuída ao desempenho; 2) número de relações matemáticas executadas corretamente: tempo médio e velocidade média, ou seja, o aluno não executou nenhuma, uma ou as duas relações matemáticas; assim, quanto maior o número de relações matemáticas executadas corretamente, maior o desempenho e; 3) número de correspondências corretas entre os cálculos do tempo médio e da velocidade média, ou seja, o cálculo do tempo médio foi aplicado corretamente ao cálculo da respectiva velocidade média, quanto maior for esse número, maior será o desempenho.

A partir da escala numérica de notas, apresentada na Tabela 02, foi possível construir o diagrama da Figura 03 que permite visualizar simultaneamente as notas de Desempenhos e a distribuição de frequências dessas notas nas duas 
atividades escolares. O diagrama permite, também, observar todas as variações de Desempenho e frequências das notas para os 114 estudantes.

Figura 3 - Diagrama com as notas de desempenho e frequências dessas notas para os 114 estudantes do estudo na AMCE e na AT

Frequência das Notas de Desempenho na Avaliação Trimestral - AT

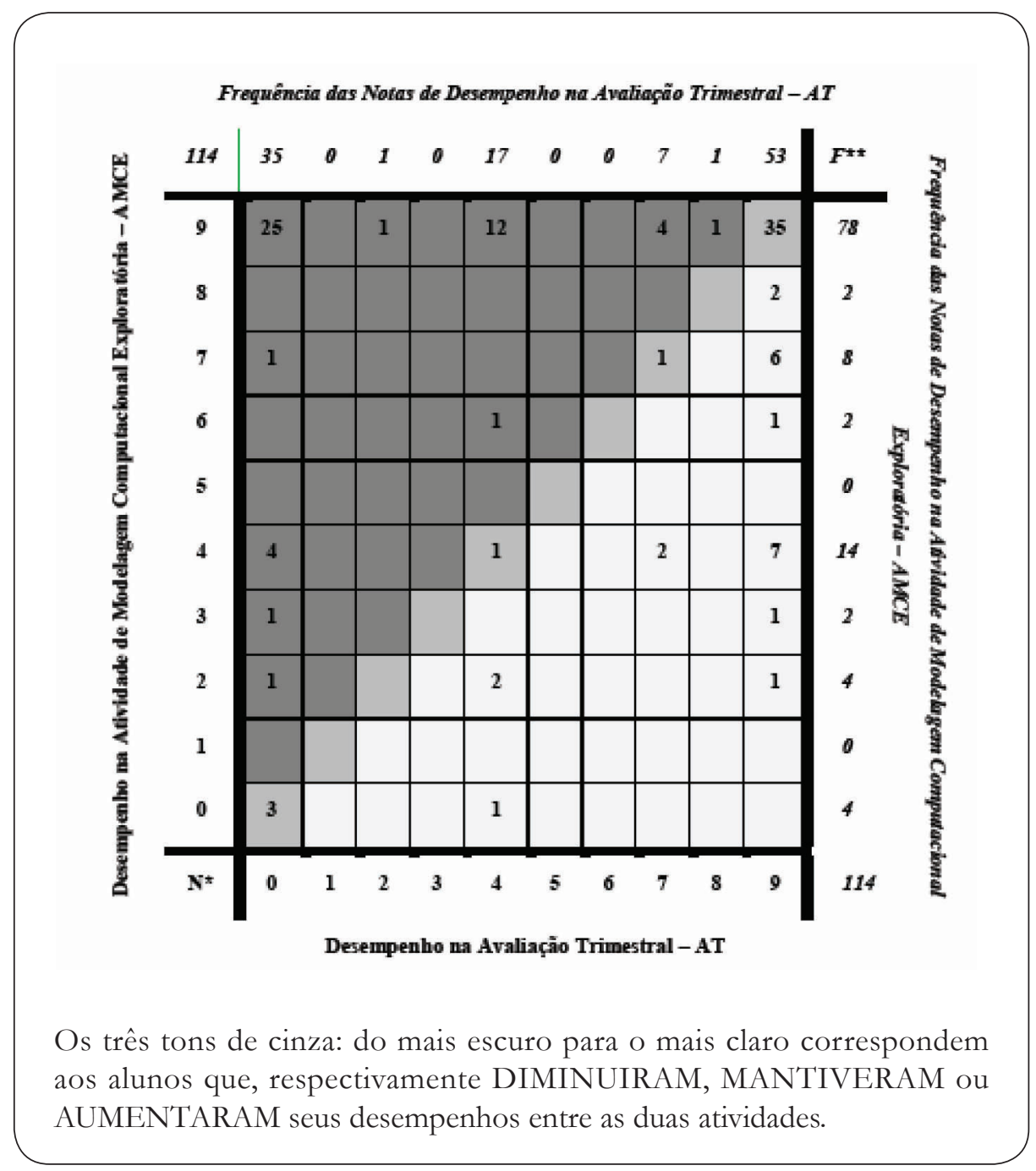

Como se pode observar na Figura 03, o diagrama possui quatro eixos: dois horizontais e dois verticais. Os eixos vertical à esquerda e horizontal inferior, representam as notas do Desempenho na AMCE e na AT, respectivamente. Nessa mesma perspectiva, os eixos vertical à direita e horizontal superior representam as 
Frequências das Notas na AMCE e na AT, respectivamente. Por fim, pode-se observar que o diagrama é dividido em três partes - região superior, diagonal principal e região inferior. Essas partes/regiões representam, respectivamente, os alunos que diminuíram, mantiveram ou aumentaram seu desempenho de uma atividade escolar para outra.

Dessa forma, por exemplo, na quinta linha de baixo para cima, encontram-se 14 alunos, eixo vertical à direita, que obtiveram uma nota de Desempenho igual a 4 na AMCE, eixo também na vertical, porém, à esquerda. Considerando-se, agora, o eixo inferior na horizontal, pode-se observar que desses 14 alunos - 07 aumentaram suas notas para 9 e 02 para 7; 01 estudante manteve sua nota constante em 4; 04 educandos diminuíram suas notas para 0. Por fim, considerando-se o eixo horizontal superior, têm-se as frequências totais dessas notas na AT; neste exemplo, tais frequências são, respectivamente, 53, 7, 17 e 35.

Assim, a partir dessa perspectiva de análise, o primeiro aspecto que será apresentado aqui é a variação total das notas de Desempenho dos 114 estudantes entre as duas atividades escolares. O diagrama mostra que essas notas diminuíram para 51 estudantes $(\approx 44,7 \%$ do total $)$, foram mantidas constantes para $40(\approx$ $35,1 \%$ ) e, por fim, aumentaram para $23(\approx 20,2 \%)$.

Dessa forma, pode-se observar inicialmente, a partir do diagrama da Figura 03, que dos 51 estudantes que diminuíram suas notas da primeira para a segunda atividade escolar, região superior do diagrama, 25 deles $(\approx 1 / 2$ de 51 ) tiveram suas notas diminuídas de 9 para 0 . Assim, esse número revela que uma quantidade considerável de educandos conseguiu desenvolver integralmente as relações matemáticas de Média Simples e Velocidade Média, apenas na AMCE; por outro lado, na $\mathbf{A T}$, tais relações matemáticas não foram desenvolvidas por esses alunos.

Neste momento, algumas considerações serão utilizadas para explicar o fato de esse grupo de estudantes ter suas notas diminuídas de 9 para 0, são elas: 1) na atividade de modelagem computacional, os alunos trabalharam em duplas com apenas um roteiro de atividades; tal situação favoreceu o maior empenho de apenas um dos estudantes na efetivação dos cálculos no roteiro de atividades, cabendo ao outro aluno a tarefa de simular e informar os dados numéricos produzidos; 2) falta de pré-requisitos matemáticos dos alunos para o desenvolvimento desse estudo específico de movimentos dos corpos, já apontado por Magalhães e colaboradores (2002), e 3) falta de um real engajamento nas atividades promovidas no laboratório de informática, pois, em tais atividades, os educandos tinham o auxílio do professor quando necessário, tanto para a execução das simulações e verificação dos dados numéricos produzidos quanto em eventuais dúvidas nos procedimentos de cálculo. Assim, a conjunção desses três fatores, explica, em sua quase totalidade, esse decréscimo tão acentuado de desempenho para esses 25 alunos.

Observando ainda os alunos que diminuíram seu Desempenho, temos que 
18 alunos também o fizeram a partir da nota 9. Desse total, tem-se que 1 estudante diminuiu para a nota 2 , o que evidencia que, na AT, tal aluno desenvolveu apenas de forma parcial a relação matemática de Média Simples. Para 12 alunos que tiveram suas notas diminuídas para 4, pode-se concluir que, na AT, tais educandos conseguiram desenvolver todos os cálculos de Média Simples; 4 alunos diminuíram suas notas para 7, e 1 aluno para 8, ou seja, tais estudantes conseguiram desenvolver os procedimentos matemáticos de cálculo da Média Simples e Velocidade Média quase integralmente na AT.

Para os outros 8 alunos restantes, que também diminuíram seu Desempenho entre as duas atividades escolares, é possível observar no diagrama da Figura 3 que 1 educando o fez a partir da nota 7, ou seja, desenvolveu, de forma quase integral, os cálculos de Média Simples e Velocidade Média na AMCE. Esse aluno diminuiu sua nota para 0, pois não desenvolveu nenhum dos cálculos na AT. Para os 7 alunos restantes, tem-se que: 1 aluno diminuiu da nota 6 para 4; 04 estudantes diminuíram da nota de 4 para 0; 01 educando diminuiu da nota 3 para 0 , e 01 aluno diminuiu de 2 para 0 .

Dessa forma, pode-se concluir que dos estudantes que diminuíram seus Desempenhos entre as duas atividades escolares, 43 deles obtiveram inicialmente a nota máxima de 9, ou seja, desenvolvendo a atividade de modelagem computacional exploratória por completo. Para os outros 8 educandos que também diminuíram suas notas, observa-se que tal decréscimo ocorreu respectivamente a partir das notas 7, 6, 4, 3 e 2. Desse total de 51 estudantes, existe o número considerável de 25 alunos que tiveram suas notas diminuídas acentuadamente, ou seja, do máximo para o mínimo.

Continuando a análise da Figura 3, tem-se, na diagonal principal, o número total de 40 alunos que mantiveram seus Desempenhos nas duas atividades escolares. Desse total, tem-se que 35 (aproximadamente 1/3 do total de 114 estudantes) mantiveram as suas notas no valor máximo de 9 , ou seja, para esses alunos o desenvolvimento dos procedimentos matemáticos para o cálculo da Média Simples e Velocidade Média foi realizado de forma integral tanto na AMCE quanto na AT.

Para os outros 5 estudantes que mantiveram seus Desempenhos nas duas atividades, tem-se que dos 5, 01 estudante manteve a nota em 7, significando que, para ele, houve o desenvolvimento dos dois tópicos em estudo quase de forma integral nas duas atividades. Ainda, dentre os 5, observa-se que 01 aluno manteve sua nota em 4, desenvolvendo, de forma correta, o cálculo da Média Simples nas duas atividades. Por fim, tem-se 3 estudantes que mantiveram suas notas em 0 (zero), o que evidencia para eles que nenhum dos dois cálculos trabalhados nessas atividades foi desenvolvido corretamente em ambas as atividades.

Assim, para esses 40 estudantes que mantiveram as mesmas notas nas duas atividades escolares, observa-se que 35 mantiveram a nota em 9, ou seja, aproximadamente $87,5 \%$ desse subtotal, e para os outros 5 alunos, as notas foram mantidas em 7 , 4 e 0 .

$\mathrm{Na}$ região inferior do diagrama da Figura 3, tem-se o grupo de 23 alunos que 
aumentaram suas notas entre as duas atividades. Assim, para esse grupo, há 2 alunos que aumentaram suas notas de 8 para 9; 6 educandos que aumentaram suas notas de 7 para 9, e 1 aluno que aumentou a sua nota de 6 para 9.

Observa-se que para esses 9 estudantes que aumentaram suas notas, o desenvolvimento quantitativo dos cálculos da Média Simples e Velocidade Média foi quase integral na AMCE e integral na AT.

Para os 14 estudantes restantes, verifica-se que 9 deles aumentaram suas notas a partir de 4, ou seja, na AMCE, esses alunos desenvolveram apenas os cálculos de Média Simples dos tempos de forma correta; já na AT, 2 deles desenvolveram tanto os cálculos de Média Simples de tempos, quanto parte dos cálculos de Velocidade Média corretamente, ficando, dessa forma, com a nota 7.

Por outro lado, 7 desses nove alunos aumentaram seu Desempenho para 9. Para os últimos 5 estudantes, resultou que 1 aumentou sua nota de 3 para 9; 2 aumentaram de 2 para 4; 1 aumentou de 2 para 9 e, por fim, 1 aumentou de 0 para 4 .

É possível, ainda, observar que dos 23 estudantes que tiveram aumento no seu desempenho, 18 deles aumentaram para a nota máxima 9. Assim, observa-se uma tendência predominante de aumento para a nota máxima. Os outros 5 aumentaram respectivamente suas notas para 4 e 7.

Observando-se o conjunto de toda a análise descrita, tem-se que para os três grupos de alunos, a saber, os que diminuíram, mantiveram ou aumentaram suas notas de Desempenho entre as duas atividades escolares, existem três tendências de variações de desempenho predominantes, são elas: a) diminuir as notas a partir de $9 \operatorname{com} 43(\approx$ $37,7 \%$ ) alunos; b) mantê-las em 9 com $35(\approx 30,7 \%$ ) alunos; e c) aumentá-las para 9 com $18(\approx 15,8 \%)$ estudantes. Assim, esses números totalizam 96 alunos $(\approx 84,2 \%)$. Do restante de estudantes, apenas $18(\approx 15,8 \%)$ alunos não foram inseridos em nenhuma dessas três tendências predominantes por apresentarem flutuações diversas de notas de Desempenho.

\section{CONSIDERAC̣̃̃ES FINAIS}

Articulando a análise dos dados feita na seção anterior com alguns dos resultados da literatura discutidos na seção II.c, serão feitas, aqui, algumas ponderações finais sobre como o uso da modelagem computacional pode ser paulatinamente incorporado ao cotidiano das salas de aulas.

Nessa perspectiva, em primeiro lugar, Fiolhais e Trindade (2003) destacam que o uso do computador para estudos de tópicos específicos de Física pode diversificar as estratégias didáticas para os professores, bem como gerar novas possibilidades de aprendizado para os alunos. Portanto, no estudo aqui apresentado, foi possível observar que, na AMCE o professor e os alunos assumiram, no processo de desenvolvimento dessa atividade, funções/papéis diferenciados, quando comparados às atividades desenvolvidas no formato tradicional, por exemplo, em uma avaliação trimestral (AT). Durante o desenvolvimento da AMCE, o professor não atuou como 
o único detentor das informações e do conhecimento, mas, sim, como um orientador da atividade, sendo solicitado pelos alunos apenas quando esses tinham dúvidas no procedimento das simulações e/ou no desenvolvimento matemático dos conceitos em estudo. Assim, coube aos alunos, por exemplo, simular o modelo computacional de um conteúdo curricular específico, produzir dados, construir bancos de dados no formato de tabelas e testar o modelo para concluir sobre os questionamentos propostos no roteiro de atividades.

Dessa forma, é possível entender que essa maior autonomia dos estudantes, principalmente na manipulação do modelo e produção dos dados na AMCE, possa ter promovido um maior engajamento desses estudantes na primeira parte do estudo, com a consequente alteração dos seus desempenhos na direção de uma melhoria quando comparados à segunda parte, ou seja, na AT, como a análise do diagrama da Figura 3 parece indicar.

Um segundo aspecto de análise é levantado por Magalhães et al. (2002) que sugere que o engajamento dos alunos parece aumentar quando realizam estudos de tópicos de Física com modelos computacionais. Assim, observa-se, nessa investigação, que tal hipótese pôde ser parcialmente verificada e corroborada, pois, de acordo com o diagrama da Figura 3, as frequências das maiores notas ocorreram na AMCE e não na AT: é importante relembrar que a AMCE não entrou no cálculo da média trimestral da nota final dos alunos. Dessa forma, tem-se que 78 alunos obtiveram nota máxima na AMCE, enquanto 53 obtiveram tal nota na AT. Por outro lado, a maior frequência de notas mínimas, ou seja, zero (0), ocorreu na AT, com 35 alunos, enquanto na AMCE foram apenas 4 .

Contudo, apesar de o engajamento dos alunos nas atividades com modelagem computacional tender a ser maior quando comparado com a atividade escolar tradicional, não é possível inferir, de forma categórica, que o desempenho deles também o será. Essa tendência pode ser explicada, também, pelo fato de o conteúdo trabalhado na perspectiva da modelagem computacional necessitar, muitas vezes, de condições atípicas do cotidiano da sala de aula, fator esse que pode contribuir para as diferenças das frequências de notas máximas e mínimas relatadas no parágrafo anterior. Neste estudo, por exemplo, o desenvolvimento dos conceitos de Média Simples e Velocidade Média, a partir do uso da modelagem computacional, ocorreu no laboratório de informática, com auxílio do professor e com os alunos organizados em duplas, condições essas que não foram reproduzidas na AT.

De toda forma, se a tendência de maior engajamento dos alunos em estudos de conceitos curriculares específicos na perspectiva da modelagem computacional se verificar de uma maneira geral e não apenas em estudos pontuais com circunstâncias específicas, tal tendência poderá ser uma perspectiva promissora para um melhor desempenho dos educandos no estudo de tópicos em ciências.

Dessa forma, este estudo indica que o uso da modelagem computacional pode ser incorporado no dia a dia da escola, e não apenas em estudos pontuais e exploratórios feitos de maneira esparsa. Obviamente, não se pretende, com essa afirmação, fazer da modelagem computacional a única e/ou a melhor perspectiva para se abordar os con- 
teúdos de Física, mas, sim, fazer dessa uma metodologia que possa ser usada de forma inovadora e que, acima de tudo, incorpore-se paulatinamente ao cotidiano escolar com maior ênfase.

Por fim, e mesmo que de forma parcial, pode-se concluir com este estudo que a modelagem computacional pode ser utilizada como geradora de novas estratégias didáticas por parte dos professores para promover um maior engajamento do estudante nas atividades escolares propostas e, dessa forma, levar esse estudante a engajar-se, por si mesmo, no processo de aprendizagem, ou seja, no processo de aprendizagem exploratória de Física.

\section{NOTAS}

${ }^{1}$ Agradecimento: Trabalho parcialmente financiado por: CNPq, CAPES, FACITEC \& FAPES.

${ }^{2}$ A rigor, o PISA (Programme for International Student Assessment ou Programa Internacional para a Avaliação de Alunos) é uma iniciativa internacional de avaliação comparada, aplicada atualmente em 65 países, que seleciona estudantes entre 15 anos e três meses e 16 anos e dois meses de idade para serem avaliados em três áreas do conhecimento - Leitura, Matemática e Ciências.

${ }^{3} \mathrm{O}$ Ambiente de Modelagem Computacional Qualitativo denominado ModeLab ${ }^{2 \mathrm{D}}$ pode ser baixado no endereço < http://modelab2.modelab.org/ $>$, juntamente com o Manual do Usuário, que apresenta uma descrição detalhada desse aplicativo.

${ }^{4}$ Para essa revisão bibliográfica, foram consultados volumes dos últimos dez anos dos periódicos Revista Brasileira de Ensino de Física, Ensaio Pesquisa em Educação em Ciência e Revista Electrónica de Enseñanza de las Ciências.

${ }^{5} \mathrm{O}$ objetivo da Figura 2 é mostrar, de forma ilustrativa, a estrutura do Roteiro de Atividades, mas não se pretende, com essa figura, que tal roteiro possa ser lido ou observado em detalhes. Contudo, tal roteiro configura, segundo Borges (2002), uma atividade investigativa de nível 1, ou seja, o Problema é dado, os Procedimentos de investigação são dados e as Conclusões são abertas.

\section{REFERÊNCIAS}

ARANHA M. L. de A. História da Educação. 2. ed. São Paulo: Moderna, 2003.

ARAUJO, I. V.; VEIT, E. A.; MOREIRA, M. A. Um estudo sobre o desempenho de alunos de Física usuários da ferramenta computacional Modellus na interpretação de gráficos em Cinemática. Instituto de Física - UFRGS - 91501-970 Porto Alegre, RS. 2007. Em: <http://www.if.ufrgs.br/cref/ntef/producao/IV_ENPEC.pdf> Acesso em: 31 de Março de 2014.

BORGES, A. T. Novos rumos para o Laboratório Escolar de Ciências. Caderno Brasileiro de Ensino de Física, Florianópolis: Santa Catarina, v. 19, n. 3, p. 291-313, dez. 2002.

BOULTER, C.J.; GILBERT, J. K. Aprendendo Ciências através de modelos e modelagens. In: COLINVAUX, D. Modelos e educacãa em ciências. Rio de Janeiro: Ravil, 1998. 
CAMILETTI, G. G. A modelagem computacional semiquantitativa no estudo de tópicos de ciências: um estudo exploratório com estudantes universitários. Dissertação (Mestrado em Física) - Programa de Pós-Graduação em Física da Universidade Federal do Espírito Santo, Vitória-ES. 2001.

DORNELES, P. F. T.; ARAÚJO, I. S.; VEIT, E. A. Simulação e modelagem computacionais no auxilio a aprendizagem significativas de conceitos básicos de eletricidade: Parte I - circuitos elétricos simples. Revista Brasileira de Ensino de Física (RBEF), São Paulo, v. 28, n. 4, p. 487-496, 2006.

FERRACIOLI, L. A integraşão de ambientes computacionais ao aprendizado exploratório em ciências. Projeto de Pesquisa financiado pelo CNPq. Processo 30.4785/2004-0, 2004.

FERRACIOLI, L. et al. Ambientes de modelagem computacional no aprendizado exploratório de física. Caderno Brasileiro de Ensino de Física, Florianópolis: Santa Catarina, v. 29, p. 679-707, 2012.

FEHSENFELD, K. M. A representação de fenômenos de cinemática de gases utilizando o ambiente de Modelagem Computacional Qualitativo ModeLab: Um estudo exploratório com estudantes ingressantes na Educação Superior. Tese (Doutorado em Física) - Programa de Pós-Graduação em Física da Universidade Federal do Espírito Santo, Vitória-ES. 2010.

FIOLHAIS, C.; TRINDADE, J. Física no computador: o computador como uma ferramenta no ensino e na aprendizagem das Ciências Físicas. Revista Brasileira de Ensino de Física (RBEF), São Paulo, v. 25, n. 3, p. 259 - 272, 2003.

GOMIDE, Camilo. Desempenho do Brasil melhora, mas, ainda estamos longe de uma educação de qualidade. Boletim da Educação, Editora Abril, 2010. Em: < http://educarparacrescer.abril.com.br/blog/ boletim-educacao/2010/12/07/>. Acesso em: 31 mar. 2014.

HECKLER, V.; SARAIVA, M. F. O.; , K. S. O. Uso de simuladores, imagens e animações como ferramentas auxiliares no ensino/aprendizagem de Óptica. Revista Brasileira de Ensino de Física (RBEF),São Paulo, v. 29, n. 2, p. 267-273, 2007.

MAGALHÃES, M. G. M. et al. (2002) Utilizando tecnologia computacional na Analise Quantitativa de Movimento: uma atividade para alunos do Ensino Médio. Revista Brasileira de Ensino de Física (RBEF), São Paulo, v. 24, n. 2, p. 97-102, 2002.

MARINS, F. C. M. A utilização de diagramas causais no desenvolvimento de Atividades de Modelagem Semiquantitativa: um estudo exploratório com estudantes do Ensino Médio. Dissertação (Mestrado em Física) - Programa de Pós-Graduação em Física, Universidade Federal do Espírito Santo, UFES, Vitória/ES. 2009.

MULINARI, M. H. A utilização da Modelagem Computacional como estratégia de a,nálise de Ecossistemas Manguezais. 56 f. Trabalho de Conclusão de Curso. (Graduação em Ciências Biológicas), UFES, 2006.

OGBORN, J.; MILLER, R. Computacional issues in modelling. In: MELLAR, H. et al. (Eds.) Learning with artificial aorlds: Computer Based Modelling in the Curriculum. London: The Falmer Press, 1994. cap 5, p. 33-38.

SALES, G. L. et. al. Atividades de Modelagem Exploratória aplicada ao ensino de Física Moderna com a utilização do objeto de aprendizagem Pato Quântico. Revista Brasileira de Ensino de Física (RBEF), São Paulo, v. 30, n. 3, 3501-13, 2008.

\section{Data recebimento: 10/04/2014 \\ Data aprovação: 30/10/2015 \\ Data da versão final: 10/11/2015}

\section{Contato:}

Laércio Ferracioli,

Universidade Federal do Espírito Santo, Centro de Ciências Exatas, Departamento de Física. ModeLab - Laboratório de Tecnologias

Interativas Aplicadas à Modelagem Cognitiva

Goiabeiras - Vitória, ES - Brasil / Cep: 29075910 